\title{
Association of dietary soy genistein intake with lung function and asthma control: a post-hoc analysis of patients enrolled in a prospective multicentre clinical trial
}

\author{
${ }^{*}$ Christian Bime', Christine Y Wei ${ }^{2}$, Janet Holbrook ${ }^{2}$, Lewis J Smith ${ }^{3}$, Robert A Wise \\ 1 Johns Hopkins University School of Medicine - Pulmonary and Critical Care Medicine, Johns Hopkins Asthma and Allergy Center, Baltimore, \\ Maryland, USA \\ 2 Johns Hopkins University, Bloomberg School of Public Health Epidemiology, Baltimore, Maryland, USA \\ ${ }^{3}$ Northwestern University Feinberg School of Medicine, Chicago, Illinois, USA
}

Received 12th June 2012; revised 27th June 2012; accepted 6th July 2012; online 10th August 2012

\begin{abstract}
Background: Broad dietary patterns have been linked to asthma but the relative contribution of specific nutrients is unclear. Soy genistein has important anti-inflammatory and other biological effects that might be beneficial in asthma. A positive association was previously reported between soy genistein intake and lung function but not with asthma exacerbations.

Aims: To conduct a post-hoc analysis of patients with inadequately controlled asthma enrolled in a prospective multicentre clinical trial to replicate this association.

Methods: A total of 300 study participants were included in the analysis. Dietary soy genistein intake was measured using the Block Soy Foods Screener. The level of soy genistein intake (little or no intake, moderate intake, or high intake) was compared with baseline lung function (pre-bronchodilator forced expiratory volume in 1 second $\left(\mathrm{FEV}_{1}\right)$ ) and asthma control (proportion of participants with an episode of poor asthma control (EPAC) and annualised rates of EPACs over a 6-month follow-up period.

Results: Participants with little or no genistein intake had a lower baseline FEV 1 than those with a moderate or high intake (2.26L vs. $2.53 \mathrm{~L}$ and $2.47 \mathrm{~L}$, respectively; $\mathrm{p}=0.01$ ). EPACs were more common among those with no genistein intake than in those with a moderate or high intake ( $54 \%$ vs. $35 \%$ vs. $40 \%$, respectively; $p<0.001$ ). These findings remained significant after adjustment for patient demographics and body mass index.

Conclusions: In patients with asthma, consumption of a diet with moderate to high amounts of soy genistein is associated with better lung function and better asthma control.

(C) 2012 Primary Care Respiratory Society UK. All rights reserved.

C Bime et al. Prim Care Respir J 2012; 21(4): 398-404

http://dx.doi.org/10.4104/pcrj.2012.00073
\end{abstract}

Keywords asthma, asthma control, diet, lung function, soy genistein

\section{See linked editorial by Varraso \& Camargo Jr on pg 367}

The full version of this paper, with online appendix,

is available online at www.thepcrj.org

\section{Introduction}

Dietary intake is increasingly recognised as an important risk factor for asthma. ${ }^{1,2}$ Over the past two decades, epidemiological studies in economically advanced countries have revealed a temporal association between an increase in asthma prevalence and decreased consumption of fresh fruits, green vegetables, and other dietary sources of antioxidants. ${ }^{3-5}$ Large cross-sectional studies have also shown that the prevalence of asthma and respiratory symptoms is lower in populations with high intake of foods of plant origin..$^{6-11}$ Despite evidence linking broad dietary patterns to asthma, the relative contributions of specific nutrients is not clear. ${ }^{12-16}$ In case-

\footnotetext{
* Corresponding author: Dr Christian Bime, Johns Hopkins University School of Medicine - Pulmonary and Critical Care Medicine, Johns Hopkins Asthma and Allergy Center, 5501 Hopkins Bayview Circle, Baltimore, Maryland 21224-6801, USA.

Tel: 4106140679 Fax: 4432875797 E-mail: cbimeny1@jhmi.edu; bimechris@gmail.com
} 
control and cross-sectional studies, high vitamin C intake was associated with a reduced risk of asthma. ${ }^{6,16}$ However, subsequent longitudinal studies and randomised placebo-controlled trials of vitamin $C$ as a supplement in asthma did not show any effect on clinical asthma control. ${ }^{6}$ In longitudinal studies, a high vitamin E intake was associated with low levels of serum lgE levels in adults and reduced asthma incidence. ${ }^{17,18}$ However, 6 weeks of supplementation with vitamin $\mathrm{E}$ in a randomised placebo-controlled fashion did not show any clinical benefit. ${ }^{19}$ Similarly, longitudinal studies and randomised controlled trials have not shown a clear protective effect from vitamin $A$ and $\beta$-carotene despite suggestions of possible benefit in cross-sectional studies. ${ }^{17,20,21}$ The potential beneficial effects in asthma of several minerals have also been studied. ${ }^{2,6}$ A low selenium intake was initially thought to be associated with asthma and airway hyper-responsiveness, but a randomised placebo-controlled study did not show any benefit on objective markers of disease. . $^{6,13}$

It has been suggested that ingestion of nutrients with antiinflammatory effects may modify asthma and diminish the severity. ${ }^{22}$ Genistein, a soy isoflavone, is one such nutrient. In animal studies, soy genistein has important biological effects that could lead to reduced inflammation and improved bronchial muscle relaxation. ${ }^{23-32}$ These include non-specific inhibition of tyrosine kinase, ${ }_{,}^{25}$ attenuation of antigen-induced airway contraction, ${ }^{27}$ attenuation of antigeninduced airway inflammation and hyper-responsiveness, ${ }^{28}$ inhibition of allergen-induced tissue eosinophilia, ${ }^{30}$ and inhibition of tryptaseinduced DNA synthesis. ${ }^{27}$ Genistein also induces apoptosis and prevents activation of nuclear factor-kappa $B(N F-\kappa B)$, thus reducing the number of total and CD4+ lymphocytes. ${ }^{24,31,32}$ These properties indicate that genistein may have a positive effect in asthma. However, there is currently no direct evidence in the literature linking high soy genistein dietary consumption with a decrease in the prevalence of asthma or allergic diseases.

In a cross-sectional analysis of participants with a wide range of asthma severity enrolled in a multicentre clinical trial, the Block food frequency questionnaire, a general food frequency questionnaire, was used to estimate the daily intake of several nutrients including vitamin $A$, vitamin $C$, vitamin $E$, carotenoids, and soy genistein..$^{22}$ Of these nutrients, only soy genistein had a significant positive association with lung function as measured by pre-bronchodilator forced expiratory volume in 1 second $\left(\mathrm{FEV}_{1}\right)$ and percent predicted peak expiratory flow rate (PEF). ${ }^{22}$ There was no association between estimated daily intake of any of the nutrients and asthma exacerbations over a 2-week follow-up period. ${ }^{22}$

Our objective was to conduct a replication study of the association between soy genistein intake and lung function in a group of patients with poorly controlled asthma. In the previous study, soy genistein intake was assessed using a general food frequency questionnaire. ${ }^{22}$ General food frequency questionnaires capture intakes from a typical US ('western') diet and thus are not suited for the measurement of phyto-oestrogen consumption because products rich in phyto-oestrogens such as soy, miso and tofu may not be part of the questionnaire database. To capture the daily intake of soy genistein more accurately, we used a modified
Block food frequency questionnaire - the Block Soy Foods Screener - which is better suited for measuring soy genistein intake. ${ }^{33,34}$ Thirdly, in the study by Smith et al.,22 the frequency of exacerbations over a follow-up period of 2 weeks was small and may have lacked adequate power to detect a significant difference. In the current analysis we assessed the relationship between soy genistein intake and asthma control over a longer follow-up period of 6 months.

\section{Methods}

\section{Participants}

Between October 2004 and May 2008 a total of 412 participants were recruited from 19 clinical centres for the parent clinical trial of esomeprazole in the treatment of poorly controlled asthma in adults. ${ }^{35}$ Data from 10 patients in New Orleans were incomplete due to Hurricane Katrina and therefore were not included in the final analysis of the parent clinical trial. Two eligible patients did not complete the Block Soy Foods screener. Also, the Block Soy Foods Screener was introduced midway in the trial when 100 patients had already completed the study so data on dietary genistein were only available for 300 of the 412 participants (Figure 1). Nonetheless, there were no differences between the study participants with soy genistein intake data and those without.

Patients selected for inclusion in the parent study had physiciandiagnosed asthma. The diagnosis of asthma was supported by either a positive methacholine challenge test or documentation of a $12 \%$ increase in $\mathrm{FEV}_{1}$ after use of a bronchodilator in the 2 years prior to enrolment. All participants were aged $\geq 18$ years and had at least 8 weeks of stable use of an inhaled corticosteroid at a dose equivalent

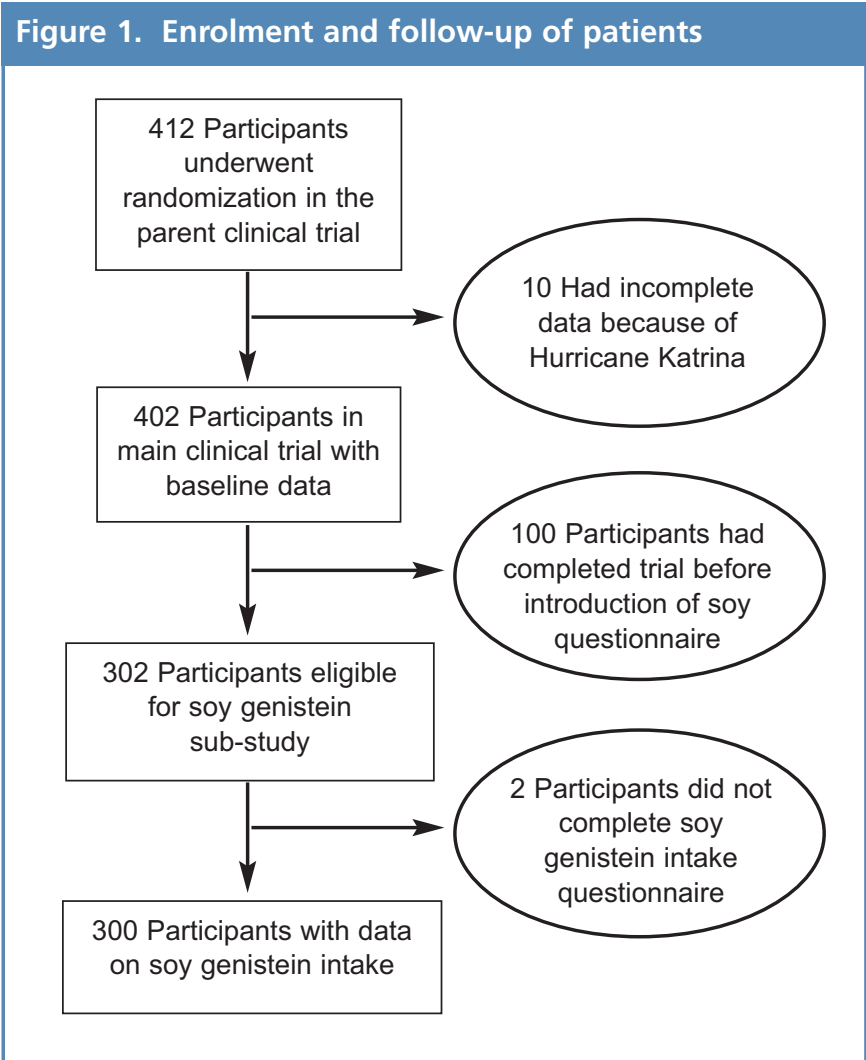


to $\geq 400 \mu \mathrm{g}$ fluticasone per day. Participants also had poor asthma control as defined by either a score on the Juniper Asthma Control Questionnaire $\left(\mathrm{ACQ}^{36}\right)$ of $\geq 1.5$ or the occurrence of more than one acute episode of asthma requiring unscheduled medical care in the previous year. Patients who had smoked cigarettes within the previous 6 months or had a history of $\geq 10$ pack-years of smoking were excluded from the study. In the parent clinical trial, treatment of patients with poorly controlled asthma and no overt symptoms of gastro-oesophageal reflux with proton pump inhibitors did not improve lung function or asthma control, ${ }^{35}$ nor was there a positive treatment effect in the $40 \%$ of participants with a positive $\mathrm{pH}$ probe study. ${ }^{35}$ The detailed methods and results for the parent clinical trial have been published elsewhere. ${ }^{35}$

\section{Procedures}

Baseline data were collected on demographic characteristics, smoking history, and soy genistein intake. Soy genistein intake was assessed using the Block Soy Foods Screener. Unlike the more general Block food frequency questionnaire, the Block Soy Foods Screener focuses on foods known to be rich in soy genistein such as tofu, soy milk or other soy beverages, soy sauce, boiled green soybeans, roasted soybeans, soy protein powder, miso soup, soy isoflavone tablets or capsules, meat substitutes made from soy, or energy bars made from soy. ${ }^{33,34}$ Completed questionnaires including estimated frequency and amount of different types of soy genisteinrich foods consumed were submitted to Berkeley Nutrition Services (Berkeley, CA) for quantification of daily intake of soy genistein. A previously developed food database detailing the content of genistein and other isoflavones in various food items has been developed and is used for quantification. ${ }^{33,34}$ Based on the type of food consumed, the estimated quantity consumed, and the frequency of consumption, the amount of genistein in micrograms per day was calculated. ${ }^{35}$ The estimated daily intake of soy genistein consumption based on the Block Soy Foods Screener has been shown to correlate well with measured urinary levels. ${ }^{34}$ Overall, this method is well accepted for assessing daily intake of genistein and other soy isoflavones and is well validated. ${ }^{34}$

Asthma symptoms were assessed using the Asthma Symptom Utility Index $\left(\mathrm{ASUI}^{37}\right)$ and asthma control was assessed using the ACQ. ${ }^{36}$ The Mini Asthma Quality of Life Questionnaire (Mini AQLQ ${ }^{38}$ ) and the Medical Outcomes Study SF-36 (QOL $\left.{ }^{39}\right)$ were used to assess the impact of asthma on quality of life. $\mathrm{FEV}_{1}$ and percent predicted $\mathrm{FEV}_{1}$ were measured using spirometry in accordance with American Thoracic Society/European Respiratory Society recommendations. ${ }^{40,41}$ To assess asthma control, morning PEF, asthma symptoms, use of rescue medication or systemic corticosteroids, and contacts with a healthcare provider for asthma symptoms were recorded daily on the diary cards by study participants or obtained at each follow-up visit for the duration of the trial.

The primary outcome measure in the parent clinical trial was the occurrence of an episode of poor asthma control (EPAC-1) defined by one or more of the following: (1) a decrease of at least 30\% in the morning PEF on two consecutive days compared with the patient's best measure during the run-in period; (2) the addition of systemic corticosteroids to treat asthma symptoms; or (3) an unscheduled contact with a healthcare provider for asthma symptoms. An expanded definition (EPAC-2) included the three components of the primary outcome measure plus an increase in the daily use of bronchodilator rescue medication ( $\geq 4$ puffs from a metered dose inhaler or $\geq 2$ uses of nebulised bronchodilator) above the average use reported during the run-in period. For counting of individual events and EPACs, once an event was noted there was a 14-day window in which no other events would contribute to the overall count. For example, if a participant had an unscheduled healthcare contact and addition of corticosteroids within 14 days, only the first event was counted as an EPAC event. Our analysis includes EPAC-1, EPAC-2, and individual components of EPACS.

The study protocol and consent statements were approved by the local institutional review board at the clinical centres and at the data coordinating centre. All participants gave informed consent.

\section{Data analyses}

Data from 300 participants who completed the dietary questionnaire were included in the analyses. Soy genistein intake among the study participants had a highly skewed distribution. There were many participants taking little or no soy genistein and few consuming very high quantities. Participants were categorised by genistein intake into high $(\geq 1500 \mu \mathrm{g} /$ day $)$, moderate $(10-1499 \mu \mathrm{g} /$ day $)$, and little or no intake $(0-9 \mu \mathrm{g} /$ day) groups. We realise that the range of participants in the moderate intake category is very large and thus a potential source of bias. However, the median intake and the mean

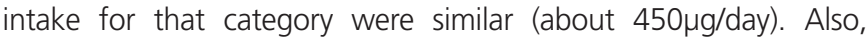
previous observational studies assessing the effect of soy genistein on cardiovascular and bone health have used similar categories. ${ }^{42-44}$

For the univariate analysis, chi-square $\left(\chi^{2}\right)$ tests were used for categorical variables and analysis of variance (ANOVA) for continuous variables to test for statistically significant differences by category of genistein intake. When there was an overall difference we examined pairwise comparisons between the different categories of genistein intake. A linear regression model was used to examine the association between the level of genistein intake, asthma questionnaire scores at baseline (JACQ, ASUI, Mini AQLQ), baseline $\mathrm{FEV}_{1}$, and proportion of patients with at least one EPAC. The adjustment covariates included race, age, gender, body mass index (BMI), and baseline FEV 1 . Use of oral corticosteroid in the previous year was not included in the model because there was no difference after univariate analysis. To examine the effect of gender and race on level of genistein intake, a logistic regression analysis was used with baseline $\mathrm{FEV}_{1}, \mathrm{BMI}$, and asthma questionnaire scores as adjustment covariates. In order to evaluate the association between level of genistein intake and rates of EPACs, negative binomial regression models, which account for more withdrawal among participants with frequent exacerbations, were used. ${ }^{45}$

\section{Results}

\section{Characteristics of study participants}

The mean age of the study participants was 41 years. Overall, a majority of the study participants were female (71\%), white (53\%), and obese (52\%). Secondhand smoke exposure was reported in 18\% of the participants and $19 \%$ were former smokers. The mean daily 
Table 1. Clinical and demographic characteristics of study participants by soy genistein intake

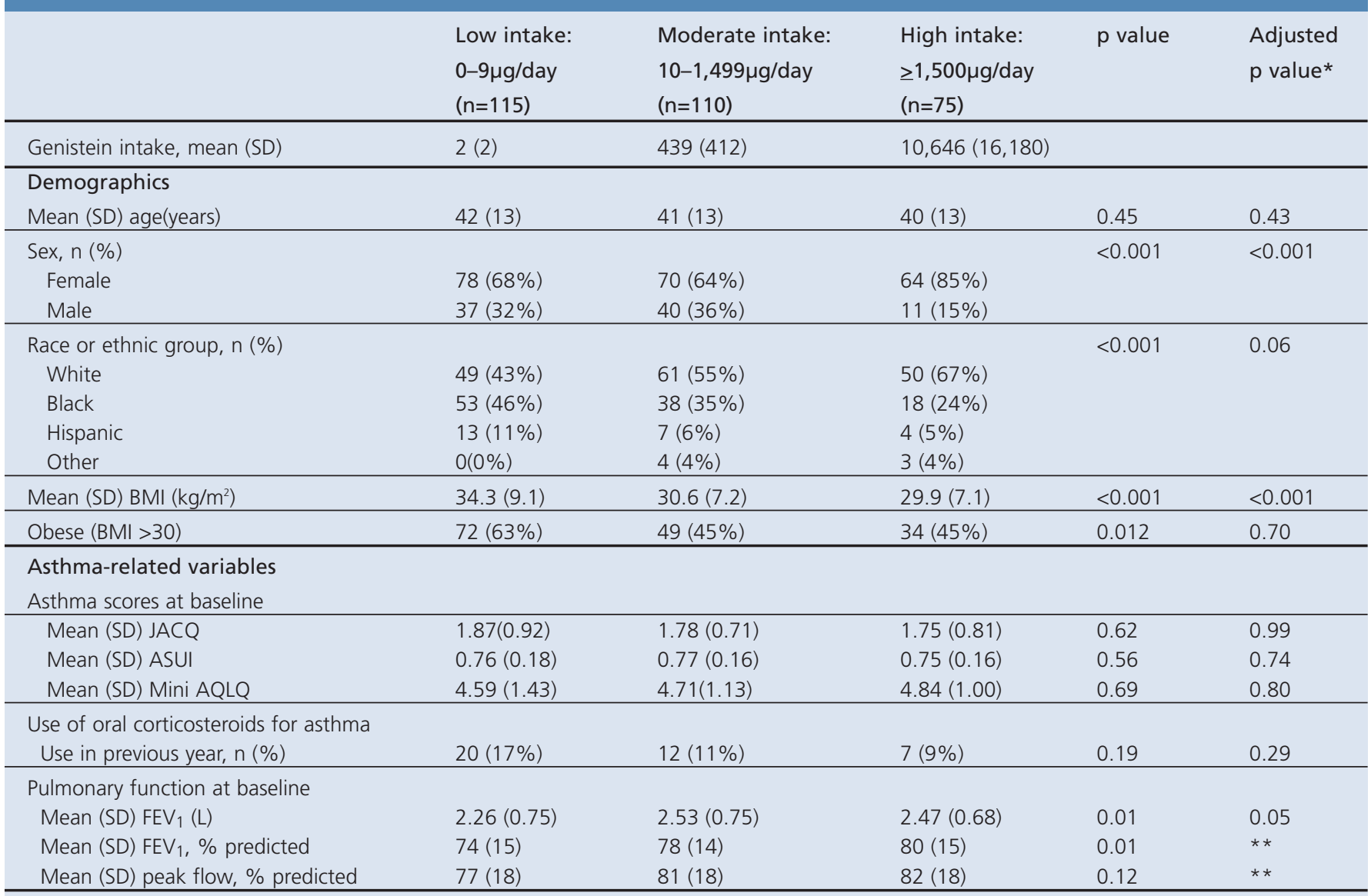

$\mathrm{BMI}=$ body mass index, JACQ=Juniper Asthma Control Questionnaire, ASUI=Asthma Symptom Utility Index, Mini AQLQ= Asthma Quality of Life Questionnaire, $\mathrm{FEV}_{1}=$ forced expiratory volume in 1 second, SD=standard deviation.

${ }^{*} \mathrm{p}$ value adjusted for age, gender, race, BMI, and baseline $\mathrm{FEV}_{1}$. **Percentage predicted values already based on age, gender, race and height so already adjusted.

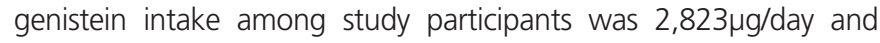
ranged from none to $11.5 \times 105 \mu \mathrm{g} / \mathrm{day}$. Roughly one-third of the participants fell into each genistein intake group with $38 \%$ classified as low intake, $37 \%$ as moderate, and $25 \%$ as high (Table 1). Those with high intake were more likely to identify themselves as white and to be female. Those with the lowest intake were more likely to identify themselves as African-American and to be obese (Table 1).

\section{Genistein intake and asthma}

Participants with little or no genistein intake had lower baseline lung function as measured by the pre-bronchodilator $\mathrm{FEV}_{1}$ and percent predicted pre-bronchodilator $\mathrm{FEV}_{1}$ than those with moderate or high intake ( $p=0.01$; Table 1). There was no significant difference in percent predicted pre-bronchodilator $\mathrm{FEV}_{1}$ between participants with moderate genistein intake and those with a high intake. There were no significant associations between the level of soy genistein intake and baseline asthma symptoms (ASUI), asthma control (ACQ), and asthma-related quality of life (Mini AQLQ).

The proportion of participants with at least one episode of poor asthma control (EPAC-1) during follow-up was significantly higher in the category with little or no genistein intake (54\%) compared with those with moderate genistein intake (35\%) or high genistein intake $(40 \%)(p=0.01$; Table 2). This difference remained significant after adjusting for age, race, gender, BMI, and baseline $\mathrm{FEV}_{1}(p=0.03)$. Due to the absence of information on socioeconomic status in this post-hoc analysis, we could not adjust for this important potential confounder. There was no significant difference between participants with moderate and high genistein intake with regard to the proportion of participants with an EPAC- $1 \quad(p=0.16)$. The unadjusted annualised rates of EPAC-1 did not differ significantly by category of genistein intake $(p=0.15)$. After adjustment, the annualised rates of EPAC-1 were significantly different among the three groups with the highest rate in the group with low intake $(p=0.04$; Table 2). It was not clear which component of EPAC-1 contributed to the observed difference. The proportion of participants with a fall in PEF of $\geq 30 \%$ from baseline for two consecutive days did not differ by level of soy genistein intake $(p=0.28)$. A significantly lower proportion of participants with medium soy genistein intake (14\%) had a new use of oral corticosteroid for asthma during the 6 months of follow-up compared with those with low genistein intake $(27 \%)$ and those 
Table 2. Asthma control during follow-up

\begin{tabular}{|c|c|c|c|c|c|}
\hline & $\begin{array}{l}\text { Low intake: } \\
0-9 \mu \mathrm{g} / \mathrm{day} \\
(\mathrm{n}=115)\end{array}$ & $\begin{array}{l}\text { Moderate intake: } \\
10-1,499 \mu \mathrm{g} / \text { day } \\
(\mathrm{n}=110)\end{array}$ & $\begin{array}{l}\text { High intake: } \\
\geq 1,500 \mu \mathrm{g} / \text { day } \\
(\mathrm{n}=75)\end{array}$ & $p$ value & $\begin{array}{l}\text { Adjusted } \\
\text { p value* }\end{array}$ \\
\hline \multicolumn{6}{|l|}{ Asthma EPAC-1 } \\
\hline Events, $\mathrm{n}$ & 134 & 111 & 81 & & \\
\hline Patients with $\geq 1$ events (\%) & $62(54 \%)$ & $38(35 \%)$ & $30(40 \%)$ & 0.01 & 0.03 \\
\hline Rate, events/person-yr & 2.6 & 2.4 & 2.5 & 0.15 & 0.04 \\
\hline \multicolumn{6}{|l|}{ EPAC-1 Components } \\
\hline \multicolumn{6}{|l|}{ Peak flow, 30\% drop } \\
\hline Events, $\mathrm{n}$ & 86 & 99 & 56 & & \\
\hline Patients with $\geq 1$ events (\%) & $36(31 \%)$ & $32(29 \%)$ & $15(21 \%)$ & 0.28 & 0.41 \\
\hline Rate, events/person-yr & 1.7 & 2.1 & 1.8 & 0.16 & 0.06 \\
\hline \multicolumn{6}{|c|}{ New use of oral corticosteroids } \\
\hline Events, $\mathrm{n}$ & 33 & 17 & 28 & & \\
\hline Patients with $\geq 1$ events (\%) & $31(27 \%)$ & $15(14 \%)$ & $24(32 \%)$ & 0.01 & 0.01 \\
\hline Rate, events/person-yr & 0.6 & 0.4 & 0.9 & 0.41 & 0.27 \\
\hline \multicolumn{6}{|c|}{ Unscheduled healthcare contact } \\
\hline Events, $\mathrm{n}$ & 42 & 12 & 26 & & \\
\hline Patients with $\geq 1$ events (\%) & $27(23 \%)$ & $12(11 \%)$ & $16(21 \%)$ & 0.04 & 0.05 \\
\hline Rate, events/person-yr & 0.8 & 0.3 & 0.8 & 0.27 & 0.22 \\
\hline \multicolumn{6}{|l|}{ Asthma EPAC-2 } \\
\hline Events, $n$ & 227 & 208 & 118 & & \\
\hline Patients with $\geq 1$ events (\%) & $76(66 \%)$ & $70(64 \%)$ & $40(53 \%)$ & 0.19 & 0.12 \\
\hline Rate, events/person-yr & 4.4 & 4.4 & 3.7 & 0.95 & 0.60 \\
\hline \multicolumn{6}{|c|}{ Increased rescue medication use } \\
\hline Events, $\mathrm{n}$ & 147 & 130 & 71 & & \\
\hline Patients with $\geq 1$ events (\%) & $47(41 \%)$ & $56(52 \%)$ & $29(41 \%)$ & 0.17 & 0.08 \\
\hline Rate, events/person-yr & 2.9 & 2.9 & 2.3 & 0.15 & 0.21 \\
\hline
\end{tabular}

with high genistein intake $(32 \%)(p=0.01)$. Similarly, a significantly lower proportion of participants with medium genistein intake $(11 \%)$ had at least one unscheduled healthcare contact for asthma during follow-up compared with those with low genistein intake $(23 \%)$ and those with high genistein intake $(21 \%)(p=0.04)$. The proportion of participants with at least one EPAC-2 and the annualised rates of EPAC-2 did not differ significantly between the three categories ( $p=0.19$; Table 2$)$.

\section{Discussion}

\section{Main findings}

In a population of poorly controlled asthmatics we confirmed the association, previously seen in patients with a wider spectrum of asthma severity, ${ }^{22}$ between soy genistein intake and lung function as measured by pre-bronchodilator FEV 1 . We also identified for the first time an association between soy genistein intake and asthma control as measured by the frequency and annualised rates of episodes of poor asthma control (EPACS) over a follow-up period of nearly 6 months. The association between soy genistein intake and lung function was consistent with a threshold effect, with the moderate and high genistein intake groups having better lung function than the low intake group. The difference in pre-bronchodilator FEV 1 between participants with low soy genistein intake and those with moderate and high genistein intake was more than $200 \mathrm{ml}$, which is the equivalent of 6-7 years of age-related lung function decline. ${ }^{46}$ For asthma control, the association with soy genistein intake appeared to be ' $U$ '-shaped with fewer episodes of poor asthma control occurring in the group with moderate genistein intake than in those with low and high intakes. The proportion of participants with new use of oral corticosteroids during follow-up was much higher than the reported use in the previous year before enrolment in the study. This difference may be due to the use of diary cards during follow-up to prospectively ascertain the occurrence of events compared with retrospective information collected at baseline. It is unlikely that the 
intake of genistein changed during the study. Also, the main trial was a negative study and it is unlikely, though possible, that a differential effect of esomeprazole could explain the difference. During the 6month follow-up period participants with medium genistein intake were significantly less likely to have a new use of oral corticosteroid or an unscheduled contact with a healthcare provider for asthma. Unlike lung function, the positive effect of soy genistein on asthma control was largely limited to those with moderate genistein intake. These findings would suggest an optimal amount of soy genistein intake that is protective in terms of asthma control. It is not clear why the beneficial effects appear to be limited to those with moderate genistein intake, nor are we aware of any mechanisms that explain this finding. During follow-up we noted statistically significant differences in the proportion of patients with new use of corticosteroids and unscheduled healthcare contact for asthma but not in the rates of these events. This is probably due to the low number of events recorded during the follow-up period.

\section{Interpretation of findings in relation to previously published work}

We also confirmed previous findings that African-Americans were more likely to consume little or no soy genistein than white participants. ${ }^{22}$ It is known that the prevalence of asthma is greater among African-Americans and they are more likely to have poorer control than white subjects. ${ }^{47}$ However, the associations between genistein intake and baseline lung function remained significant after adjustment for race. The average American diet contains 1-3mg/day soy genistein. ${ }^{48}$ Among our study participants, the mean daily genistein intake was about $2 \mathrm{mg}$ and the median intake about $0.75 \mathrm{mg}$. This quantity is low compared with Asian diets which may contain up to $60 \mathrm{mg} /$ day soy genistein. ${ }^{3.48 .51}$ It is noteworthy that the prevalence of asthma in Japan is lower than in the USA despite the same level of industrialization. ${ }^{49,52}$ Paradoxically, we found that patients with a moderate intake of soy genistein had better asthma control than those with a high intake. This finding indicates that there may be other unknown factors interacting with or confounding the relationship of soy genistein with asthma control.

\section{Strengths and limitations of this study}

Our study has limited generalisability since the majority of our participants were female, white, and obese. Also, a significantly higher proportion of female participants consumed higher amounts of soy genistein than their male counterparts. In fact, the ratio of female to male participants in the high intake group was $>5: 1$. Isoflavones are phyto-oestrogens and therefore may have differential effects based on gender. The differential soy consumption based on gender could therefore impact the results. The possible interaction between gender and obesity is another factor that could influence the findings. The findings of this study cannot be extrapolated to other asthma populations because of the unique characteristics of the study population.

We defined asthma control using EPACs. Even though these definitions have been used in randomised controlled trials, ${ }^{35}$ they are not yet the standard for reporting asthma control. However, the individual components used to define an EPAC are similar to those included in the definition of asthma exacerbations by Smith et al. ${ }^{22}$
Another limitation of our study is the use of a food frequency questionnaire to estimate soy genistein intake. In general, food frequency questionnaires depend on recall and self-report and are subject to bias and measurement error. However, estimates from the Block Soy Foods Screener have been shown to correlate with blood levels of genistein. ${ }^{34}$ Finally, our findings are observational and therefore other unknown confounders are not accounted for.

\section{Conclusions}

We have replicated the association between soy genistein intake and lung function in a population of patients with poorly controlled asthma. We have also added to what was previously known by showing that moderate genistein intake is associated with better asthma control. We are not aware of any biological mechanism of soy genistein that explains its limited benefit to the moderate intake group of our study population. It remains to be determined whether dietary supplementation with soy genistein in asthma patients with a low soy genistein intake can improve lung function measures and asthma control.

\section{Handling editor Gopal Netuveli \\ Statistical review Gopal Netuveli}

Acknowledgements See online Appendix, available at www.thepcrj.org Conflicts of interest The authors declare that they have no conflicts of interest in relation to this article.

Contributorship CB: contributed to data analysis, writing and revising the manuscript. CYW: contributed to data analysis. JH: contributed to data analysis, writing and revising the manuscript. LJS: contributed to writing and revising the manuscript. RAW: contributed to writing and revising the manuscript.

Funding This study was supported by the NIH-NHLBI (5U01HL072968) and the American Lung Association. The study is registered at ClinicalTrials.Gov: NCT00069823.

\section{References}

1. Ellwood P, Asher MI, Bjorksten B, Burr M, Pearce N, Robertson CF. Diet and asthma, allergic rhinoconjunctivitis and atopic eczema symptom prevalence: an ecological analysis of the International Study of Asthma and Allergies in Childhood (ISAAC) data. ISAAC phase one study group. Eur Respir J 2001;17(3):436-43. http://dx.doi.org/10.1183/09031936.01.17304360

2. Kim J, Ellwood P, Asher Ml. Diet and asthma: looking back, moving forward. Respir Res 2009;10(1):49. http://dx.doi.org/10.1186/1465-9921-10-49

3. Asher MI, Montefort S, Bjorksten B, et al. Worldwide time trends in the prevalence of symptoms of asthma, allergic rhinoconjunctivitis, and eczema in childhood: ISAAC phases one and three repeat multicountry cross-sectional surveys. Lancet 2006;368(9537):733-43. http://dx.doi.org/10.1016/S0140-6736(06)69283-0

4. Baker JC, Ayres JG. Diet and asthma. Respir Med 2000;94(10):925-34 http://dx.doi.org/10.1053/rmed.2000.0873

5. Devereux $\mathrm{G}$. The increase in the prevalence of asthma and allergy: food for thought. Nat Rev Immunol 2006;6(11):869-74. http://dx.doi.org/10.1038/nri1958

6. McKeever TM, Britton J. Diet and asthma. Am J Respir Crit Care Med 2004;170(7):725-9. http://dx.doi.org/10.1164/rccm.200405-611PP

7. Chatzi L, Torrent M, Romieu I, et al. Diet, wheeze, and atopy in school children in Menorca, Spain. Pediatr Allergy Immunol 2007;18(6):480-5. http://dx.doi.org/10.1111/j.1399-3038.2007.00596.x

8. Chatzi L, Apostolaki G, Bibakis I, et al. Protective effect of fruits, vegetables and the mediterranean diet on asthma and allergies among children in Crete. Thorax 2007;62(8):677-83. http://dx.doi.org/10.1136/thx.2006.069419

9. Shaheen SO, Sterne JA, Thompson RL, Songhurst CE, Margetts BM, Burney PG. Dietary antioxidants and asthma in adults: population-based case-control study. Am J Respir Crit Care Med 2001;164(10):1823-8

10. Tsai HJ, Tsai AC. The association of diet with respiratory symptoms and asthma in schoolchildren in Taipei, Taiwan. J Asthma 2007;44(8):599-603. http://dx.doi.org/10.1080/02770900701539509 
11. Okoko BJ, Burney PG, Newson RB, Potts JF, Shaheen SO. Childhood asthma and fruit consumption. Eur Respir J 2007;29(6):1161-8. http://dx.doi.org/10.1183/09031936.00097806

12. Gao J, Gao X, Li W, Zhu Y, Thompson PJ. Observational studies on the effect of dietary antioxidants on asthma: a meta-analysis. Respirology 2008;13(4):528-36. http://dx.doi.org/10.1111/j.1440-1843.2008.01286.x

13. Feary J, Britton J. Dietary supplements and asthma: another one bites the dust. Thorax 2007;62(6):466-8. http://dx.doi.org/10.1136/thx.2006.073866

14. Hoffmann PR. Selenium and asthma: a complex relationship. Allergy 2008; 63(7):854-6. http://dx.doi.org/10.1111/j.1398-9995.2008.01676.x

15. Trenga CA, Koenig JQ, Williams PV. Dietary antioxidants and ozone-induced bronchial hyperresponsiveness in adults with asthma. Arch Environ Health 2001;56(3):242-9. http://dx.doi.org/10.1080/00039890109604448

16. Kaur B, Rowe BH, Ram FS. Vitamin C supplementation for asthma. Cochrane Database Syst Rev 2001(4):CD000993.

17. Troisi RJ, Willett WC, Weiss ST, Trichopoulos D, Rosner B, Speizer FE. A prospective study of diet and adult-onset asthma. Am J Respir Crit Care Med 1995;151(5):1401-08.

18. Fogarty A, Lewis S, Weiss S, Britton J. Dietary vitamin E, IgE concentrations, atopy. Lancet 2000;356:1573-4. http://dx.doi.org/10.1016/S0140-6736(00)03132-9

19. Pearson PJK, Lewis SA, Britton J, Fogarty A. Vitamin E supplements in asthma: a parallel group randomised placebo controlled trial. Thorax 2004;59(8):652-6. http://dx.doi.org/10.1136/thx.2004.022616

20. Harik-Khan RI, Muller DC, Wise RA. Serum vitamin levels and the risk of asthma in children. Am J Epidemio/ 2004;159(4):351-7. http://dx.doi.org/10.1093/aje/kwh053

21. Huang S, Pan W. Dietary fats and asthma in teenagers: analyses of the first Nutrition And Health Survey In Taiwan (NAHSIT). Clin Exp Allergy 2001;31(12):1875-80. http://dx.doi.org/10.1046/j.1365-2222.2001.01222.x

22. Smith $\amalg$, Holbrook JT, Wise R, et al. for the American Lung Association Asthma Clinical Research Centers. Dietary intake of soy genistein is associated with lung function in patients with asthma. J Asthma 2004;41(8):833-43. http://dx.doi.org/10.1081/JAS-200038447

23. Wiseman $\mathrm{H}$. The therapeutic potential of phytoestrogens. Expert Opin Investig Drugs 2000;9(8):1829-40. http://dx.doi.org/10.1517/13543784.9.8.1829

24. Polkowski K, Mazurek AP. Biological properties of genistein. A review of in vitro and in vivo data. Acta Pol Pharm 2000;57(2):135-55.

25. Akiyama T, Ishida J, Nakagawa $S$, et al. Genistein, a specific inhibitor of tyrosinespecific protein kinases. J Biol Chem 1987;262(12):5592-5.

26. Janssen $\mathrm{L}$, Lu-Chao H, Netherton $\mathrm{S}$. Responsiveness of canine bronchial vasculature to excitatory stimuli and to cooling. Am J Physiol Lung Cell Mol Physiol 2001;280(5):L930-7.

27. Tsang F, Fred Wong WS. Inhibitors of tyrosine kinase signaling cascade attenuated antigen challenge of guinea-pig airways in vitro. Am J Respir Crit Care Med 2000;162(1):126-33.

28. Duan W, Kuo IC, Selvarajan S, Chua KY, Bay BH, Wong WSF. Antiinflammatory effects of genistein, a tyrosine kinase inhibitor, on a guinea pig model of asthma. Am J Respir Crit Care Med 2003;167(2):185-92. http://dx.doi.org/10.1164/rccm.200205-4200C

29. Berger $P$, Perng $D$, Thabrew $H$, et al. Tryptase and agonists of PAR-2 induce the proliferation of human airway smooth muscle cells. J App/ Physiol 2001;91(3):13729.

30. Regal JF, Fraser DG, Weeks CE, Greenberg NA. Dietary phytoestrogens have antiinflammatory activity in a guinea pig model of asthma. Proc Soc Exp Biol Med 2000;223(4):372-8. http://dx.doi.org/10.1046/J.1525-1373.2000.22353.x

31. Kang J, Lee HW, Lee HS, et al. Genistein prevents nuclear factor-kappa B activation and acute lung injury induced by lipopolysaccharide. Am J Respir Crit Care Med 2001;164(12):2206-12.

32. Yellayi S, Naaz A, Szewczykowski MA, et al. The phytoestrogen genistein induces thymic and immune changes: a human health concern? Proc Natl Acad Sci USA 2002;99(11):7616-21. http://dx.doi.org/10.1073/pnas.102650199
33. Pillow PC, Duphorne CM, Chang S, et al. Development of a database for assessing dietary phytoestrogen intake. Nutr Cancer 1999;33(1):3-19. http://dx.doi.org/10.1080/01635589909514742

34. Huang MH, Harrison GG, Mohamed MM, et al. Assessing the accuracy of a food frequency questionnaire for estimating usual intake of phytoestrogens. Nutr Cancer 2000;37(2):145-54. http://dx.doi.org/10.1207/S15327914NC372_5

35. American Lung Association Asthma Clinical Research Centers, Mastronarde JG, Anthonisen NR, et al. Efficacy of esomeprazole for treatment of poorly controlled asthma. N Engl J Med 2009;360(15):1487-99. http://dx.doi.org/10.1056/NEJMoa0806290

36. Juniper E, O'Byrne P, Guyatt G, Ferrie P, King D. Development and validation of a questionnaire to measure asthma control. Eur Respir J 1999;14(4):902-07. http://dx.doi.org/10.1034/j.1399-3003.1999.14d29.x

37. Revicki DA, Leidy NK, Brennan-Diemer F, Sorensen S, Togias A. Integrating patient preferences into health outcomes assessment: the multiattribute asthma symptom utility index. Chest 1998;114(4):998-1007. http://dx.doi.org/10.1378/chest.114.4.998

38. Juniper E, Guyatt G, Cox F, Ferrie P, King D. Development and validation of the mini asthma quality of life questionnaire. Eur Respir J 1999;14(1):32-8. http://dx.doi.org/10.1034/j.1399-3003.1999.14a08.x

39. Bousquet J, Knani J, Dhivert $\mathrm{H}$, et al. Quality of life in asthma. I. Internal consistency and validity of the SF-36 questionnaire. Am J Respir Crit Care Med 1994;149(2):371-5.

40. Miller MR, Crapo R, Hankinson J, et al. General considerations for lung function testing. Eur Respir J 2005;26(1):153-61. http://dx.doi.org/10.1183/09031936.05.00034505

41. Miller MR, Hankinson J, Brusasco V, et al. Standardisation of spirometry. Eur Respir J 2005;26(2):319-38. http://dx.doi.org/10.1183/09031936.05.00034805

42. Goodman-Gruen D, Kritz-Silverstein D. Usual dietary isoflavone intake is associated with cardiovascular disease risk factors in postmenopausal women. J Nutr 2001;131(4):1202-06

43. Goodman-Gruen D, Kritz-Silverstein D. Usual dietary isoflavone intake and body composition in postmenopausal women. Menopause 2003;10(5):427-32. http://dx.doi.org/10.1097/01.GME.0000058866.35869.B4

44. Kritz-Silverstein D, Goodman-Gruen D. Usual dietary isoflavone intake, bone mineral density, and bone metabolism in postmenopausal women. J Womens Health Gend Based Med 2002;11(1):69-78. http://dx.doi.org/10.1089/152460902753473480

45. Keene ON, Jones MR, Lane PW, Anderson J. Analysis of exacerbation rates in asthma and chronic obstructive pulmonary disease: example from the TRISTAN study. Pharm Stat 2007;6(2):89-97. http://dx.doi.org/10.1002/pst.250

46. Lange P, Parner J, Vestibo J, et al. A 15 -year follow-up study of ventillatory function in adults with asthma. $N$ Engl J Med 1998;339:1194-200. http://dx.doi.org/10.1056/NEJM199810223391703

47. Kamada A. A community-based study of epidemiology of asthma. Incidence rates, 1964 to 1983. Pediatrics 1994;94(2):257.

48. Michelfelder AJ. Soy: a complete source of protein. Am Fam Physician 2009;79(1):43-7.

49. Wakai K, Egami I, Kato K, et al. Dietary intake and sources of isoflavones among Japanese. Nutr Cancer 1999;33(2):139-45. http://dx.doi.org/10.1207/S15327914NC330204

50. Fukutake M, Takahashi M, Ishida K, Kawamura H, Sugimura T, Wakabayashi K. Quantification of genistein and genistin in soybeans and soybean products. Food Chem Toxicol 1996;34(5):457-61. http://dx.doi.org/10.1016/0278-6915(96)87355-8

51. Setchell KD, Cole SJ. Variations in isoflavone levels in soy foods and soy protein isolates and issues related to isoflavone databases and food labeling. J Agric Food Chem 2003;51(14):4146-55. http://dx.doi.org/10.1021/jf026199b

52. Beasley $R$, for the ISAAC Steering Committee. Worldwide variations in the prevalence of asthma symptoms: The International Study of Asthma and Allergies in Childhood (ISAAC). Eur Respir J 1998;12(2):315-35. http://dx.doi.org/10.1183/09031936.98.12020315

\section{Available online at http://www.thepcrj.org}


Appendix 1: Acknowledgements

The authors would like to acknowledge the contribution of the following American Lung Association Asthma Clinical Research Centres to this study:

Baylor College of Medicine, Houston: N A Hanania (principal investigator), M Sockrider (co-principal investigator), L Giraldo (principal clinic coordinator), R Valdez (coordinator); Columbia University-New York University Consortium, New York: J Reibman (principal investigator), E DiMango (co-principal investigator), C Cammarata and K Carapetyan (clinic coordinators at New York University), J Sormillon and E Simpson (clinic coordinators at Columbia University); Duke University Medical Center, Durham: L Williams (principal investigator), J Sundy (co-principal investigator), G Dudek (principal clinic coordinator), R Newton and A Dugdale (coordinators); Emory University School of Medicine, Atlanta: W G Teague (principal investigator), R Patel (principal clinic coordinator), J Peabody, R Patel, E Hunter, D Whitlock (coordinators); Illinois Consortium, Chicago: L Smith (principal investigator), J Moy, E Naureckas, C S Olopade (co-principal investigators), J Hixon (principal clinic coordinator), A Brees, G Rivera, S Sietsema, V Zagaja (coordinators); Indiana University, Asthma Clinical Research Center, Indianapolis: M Busk (principal investigator), F Leickly, C Williams (co-principal investigators), P Puntenney (coordinator); Jefferson Medical College, Philadelphia: F Leone (principal investigator), M Hayes-Hampton (principal clinic coordinator); Louisiana State University Health Sciences Center, Ernest N Morial Asthma, Allergy, and Respiratory Disease Center, New Orleans: W R Summer (principal investigator), C Glynn and G Meyaski (clinic coordinators); National Jewish Medical and Research Center, Denver: R Katial (principal investigator), R Gibbs (principal clinic coordinator), L Lopez, C Ruis, B Schoen (coordinators); Nemours Children's Clinic-University of Florida Consortium, Jacksonville: J Lima (principal investigator), K Blake (co-principal investigator), A Santos (principal clinic coordinator), L Duckworth, D Schaeffer, M McRae (coordinators); North Shore-Long Island Jewish Health System, New Hyde Park, New York: J Karpel (principal investigator), R Cohen (co-principal investigator), R Ramdeo (principal clinic coordinator); Northern New England Consortium (formerly Vermont Lung Center at the University of Vermont), Colchester, Vermont: C G Irvin (principal investigator), A E Dixon, D A Kaminsky, E Kent, T Lahiri, P Shapiro (co-principal investigators), S Lang (principal clinic coordinator), J Allen, A Coote, LM Doucette, K Girard, J Lynn, L Moon, T Viola, S Burns (coordinators); The Ohio State University Medical Center/Columbus Children's Hospital, Columbus: J Mastronarde (principal investigator), K McCoy (co-principal investigator), J
Parsons (co-investigator), J Drake (principal clinic coordinator), R Compton, L Raterman, D Cosmar (coordinators); University of Alabama at Birmingham, Birmingham: L B Gerald (principal investigator), W C Bailey (co-principal investigator), S Erwin (principal clinic coordinator), H Young, A Kelley, D Laken, B Martin (coordinators); University of Miami, Miami-University of South Florida, Tampa: A Wanner (principal investigator, Miami), R Lockey (principal investigator, Tampa), E Mendes (principal clinic coordinator for University of Miami), S McCullough (principal clinic coordinator for University of South Florida) B Fimbel, M Grandstaff (coordinators); University of Minnesota, Minneapolis: M N Blumenthal (principal investigator), G Brottman, J Hagen (co-principal investigators), A Decker, D Lascewski, S Kelleher (principal clinic coordinators), K Bachman, M Sneen (coordinators); University of Missouri, Kansas City School of Medicine, Kansas City: G Salzman (principal investigator), D Pyszczynski (co-principal investigator), P Haney (principal clinic coordinator); St Louis Asthma Clinical Research Center: Washington University, St Louis University, and Clinical Research Center, St Louis: M Castro (principal investigator), L Bacharier, K Sumino (co-investigators), M E Scheipeter and J Tarsi (coordinators); University of California San Diego: S Wasserman (principal investigator), J Ramsdell (co-principal investigator) J Vitin, T Tucker (clinic coordinators); Chairman's Office, Respiratory Hospital, Winnipeg, Man, Canada: N Anthonisen (research group chair); Data Coordinating Center, Johns Hopkins University Center for Clinical Trials, Baltimore: R Wise (centre director), J Holbrook (deputy director), E Brown (principal coordinator), D Amend-Libercci, K Barry, M Daniel, G Leatherman, C Levine, A Lears, R Masih, S Modak, D Nowakowski, N Prusakowski, D Shade, E Sugar, C Shiflett; Esophageal pH Probe Quality Control Center, Temple University School of Medicine: J Richter (centre director); Data and Safety Monitoring Board: S Lazarus (chair), W Calhoun, P Kahrilas, B McWilliams, A Rogatko, C Sorkness; Project Office, American Lung Association New York: E Lancet, R Vento (project officers), N Edelman (scientific consultant), S Rappaport, G Pezza; Project Office, National Heart Lung and Blood Institute: $V$ Taggart (project officer), G Weinmann (DSMB secretary, airway branch chief); ALA Scientific Advisory Committee: G Snider (chair), N Anthonisen, M Castro, J Fish, D Ingbar, S Jenkinson, D Mannino, H Perlstadt, L Rosenwasser, J Samet, T Standiford, J Smith, L Smith, D Schraufnagel, A Wanner, T Weaver. 